\title{
Malignant Blood Vessel Neoplasm
}

National Cancer Institute

\section{Source}

National Cancer Institute. Malignant Blood Vessel Neoplasm. NCI Thesaurus. Code C8538.

A malignant neoplasm arising from the blood vessels. 